IJBPAS, December, 2021, 10(12): 4740-4745

ISSN: $2277-4998$

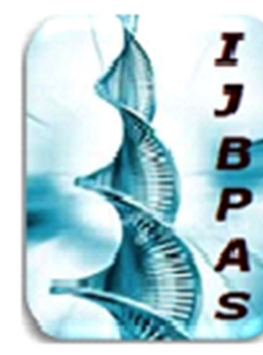

International Journal of Biology, Pharmacy

and Allied Sciences (IJBPAS)

'A Bridge Betuben Caboratory and QRendo'

WwW.ijbpas.com

\title{
HYPOCALCEMIC CONVULSIONS SECONDARY TO \\ HYPOMAGNESEMIA: A CASE REPORT
}

\section{JAGADEESWARI S}

Department of Paediatrics, Sree Balaji Medical College and Hospital,Chrompet, Chennai, 600044

*Corresponding Author: Dr. S Jagadeeswari: E Mail: drjagadeswari@gmail.com

Received 28 ${ }^{\text {th }}$ March 2021; Revised 28 ${ }^{\text {th }}$ April 2021; Accepted $25^{\text {th }}$ May 2021; Available online $1^{\text {st }}$ Dec. 2021

https://doi.org/10.31032/IJBPAS/2021/10.12.58004

\begin{abstract}
Hypomagnesemia with secondary hypocalcemia (HSH) is a rare inherited disorder, characterized by low levels of serum magnesium associated with symptomatic hypocalcemia. This condition manifests with the defect in the intestinal trans-epithelial transport system-defective intestinal absorption of magnesium, which impairs the function of the parathyroid gland. The condition typically presents in the infancy with neuromuscular excitability and convulsion refractory to antiepileptic therapy. We described a 2-year- old patient presented with generalized tonic convulsions refractory to antiepileptic therapy. The clinical examination demonstrated stiffening of handsand feet. The laboratory investigations showed severe hypomagnesemia with associated hypocalcemia. Parathyroid hormone level was in the lower normal range $(25 \mathrm{pg} . / \mathrm{mL})$. Based on the presentation and laboratory findings, magnesium sulphate intravenous (IV)and calcium (oral+I.V.) replacement therapy was initiated. Parathyroid hormone level normalized and symptoms resolved. Magnesium levels should always be investigated while confirming the etiologic basis for seizures. Early diagnosis and prompt magnesium replacement are essential to prevent death or long-term irreversible neurologic damage.
\end{abstract}

\section{Keywords: Hypomagnesemia, Hypocalcemia, Convulsions}

\section{INTRODUCTION}

Hypomagnesemia with secondary autosomal recessive condition which hypocalcemia (HSH) is a rare genetic generally presents in early childhood [1, 2]. 
There is decreased magnesium blood concentration associated with hypocalcemia, secondary to magnesium induced hypoparathyroidism [3]. The affected patients present with increased neuromuscular excitability in the form of muscle cramps, spasms or tetany and generalized convulsions with the majority of them present with latter sign [4-6]. Magnesium is normally absorbed through an active process in the intestine through a channel called transient receptor potential channel melastanin 6 (TRPM6). The same channel is responsible for the magnesium reabsorption in the kidneys. In $\mathrm{HSH}$, there is genetic mutation in this channel, that leads to the defective absorption of magnesium through the intestinal epithelium and increased clearance through kidneys $[7,8]$. The low magnesium blood concentration leads to decreased synthesis and release of parathyroid hormone and its increased target tissue resistance [9-11]. The symptoms resolve by correcting the serum magnesium level (1.5-2.5 $\mathrm{mg} / \mathrm{dL})$. The associated hypocalcemia also resolves [3]. The condition requires lifelong magnesium supplementation to keep the magnesium and calcium in normal ranges $[\mathbf{1}, \mathbf{1 1}]$. Failure to diagnose the condition in time, leads to irreversible neurologic damage [10].We report a female patient who presented with convulsions, profound hypomagnesemia with hypocalcemia. To the best of our knowledge, this is the first case we are reporting from Pakistan.

\section{CASE PRESENTATION}

A 2 year old female patient, born to Pakistani parents with no parental consanguinity, without any significant family history, presented to outpatient pediatric medicine department with stiffening of hands and feet. She has one to two episodes of convulsions daily. The first episode of convulsions was noted when she was 2-month old. Since then she was experiencing convulsions regularly. The convulsions are generalized and of tonic variety associated with shortness of breath, central cyanosis and urinary incontinence. The patient has no history of trauma or cerebrovascular accident. The patient was a febrile. She was born at term and delivered vaginally. Clinically, the neonatal status of the patient was unremarkable. Examination was unremarkable with the exception of stiffening of the hands and feet. The patient had no clinical signs of rickets and had presented to the same outpatient department twice before. Previously this was presumed to be a case of primary hypoparathyroidism and was sent home on calcium supplementation. The patient was admitted to 
the pediatric unit and was investigated. After receiving those investigations, the patient was started on parenteral magnesium sulphate and calcium gluconate therapy. The convulsions were controlled immediately after starting said therapy. Her investigations were repeated three days later as shown in

Table 1.

Complete blood count, serum electrolytes and urea were in the normal range. Beside these investigations an electroencephalogram (EEG) was also performed to rule out the possibility of an epileptic disorder, which was unremarkable.

The patient was discharged after receiving the above investigations and was prescribed Oral magnesium sulphate (thrice a day), oral calcium and vitamin D drops as home medications. The same patient was followed further in time with the laboratory reports given in Table1.

\section{DISCUSSION}

$\mathrm{HSH}$ is a rare inherited disorder characterized by very low magnesium levels associated with hypocalcemia [1]. The hypocalcemia is secondary to parathyroid failure and parathyroid hormone resistance at organ level [3]. HSH typically presents in early infantile age with signs of increased neuromuscular excitability (muscle spasms or tetany) or generalized convulsions [2-
5]. Failure to diagnose and start the therapy in time, may result in serious neurologic sequelae [10]. The underlying pathophysiology of $\mathrm{HSH}$ is related to the defective trans- epithelial transport of magnesium in the intestine and increased renal clearance. Mutation in the gene encoding the TRPM6 has been linked to the defective absorption of magnesium through intestine and increased renal clearance $[7,8]$. Our patient has the typical presentation of HSH i.e generalized convulsions refractory to vitamin $\mathrm{D}$, calcium and anticonvulsant therapy.

Shalev et al reported generalized convulsions as the most common presenting event, with the mean age of 4.9 weeks [6].

The unresponsiveness to vitamin D ruled out rickets (nutritional insufficiency). The unresponsiveness to the calcium supplementation and parathyroid hormone levels in the lower normal range ruled out the possibility of parathyroid disorder. Similarly, electroencephalogram taken of the patient was unremarkable. Serum magnesium levels were low $(0.37 \mathrm{mg} / \mathrm{dL})$. Parenteral magnesium and calcium supplementation therapy was initiated. The symptoms reversed immediately without the need of further anticonvulsant therapy. Serum calcium and magnesium levels obtained three 
days later were $9.53 \mathrm{mg} / \mathrm{dL}$ and $1.28 \mathrm{mg} / \mathrm{dL}$ respectively. The acute reversal of clinical symptoms with intravenous magnesium supplementation and normalization of serum calcium were suggestive of HSH. Shalev et al also reported that despite high doses of enteral magnesium, the blood concentration of those patients was still in the subnormal range [6].

Due to affordability issue and the relief of clinical symptoms with magnesium supplementation, genetic analysis of the patient was not done. Early recognition and treatment compliance can prevent permanent neurologic damage [6]. The patient was started on lifelong oral magnesium supplementation. The follow-up period was of good neurologic outcome.

\section{CONCLUSION}

$\mathrm{HSH}$ is a rare disorder manifesting with convulsions and spasms in early infancy, which if left untreated, can lead to mental retardation or death. The diagnosis can be a challenge, and a high index of suspicion is needed. An inherited disorder should be suspected, and genetic studies are recommended. A simple magnesium salt supplementation can prevent permanent neurologic damage. Early diagnosis and prompt magnesium replacement are essential to prevent death or long-term neurodevelopmental sequelae. Magnesium shouldalways be investigated while confirming the etiologic basis for seizures. Hypomagnesemia and afebrile seizures should be treated with the goal of maintaining a magnesium concentration > $1.7 \mathrm{mg} / \mathrm{dL}$.

\begin{tabular}{|c|c|c|c|c|c|c|c|c|}
\hline \multirow[b]{2}{*}{ Parameter } & \multirow{2}{*}{$\begin{array}{l}\text { Normal } \\
\text { Range }\end{array}$} & \multicolumn{2}{|c|}{ Previous visits } & \multicolumn{2}{|c|}{ Current visit } & \multirow{2}{*}{$\begin{array}{l}\text { Follow up } \\
\left.\text { visit(1 }{ }^{\text {st }}\right)\end{array}$} & \multirow{2}{*}{$\begin{array}{l}\text { Follow up } \\
\text { visit(2nd })\end{array}$} & \multirow{2}{*}{$\begin{array}{l}\text { Follow up } \\
\left.\text { visit( } 3^{\text {rd }}\right)\end{array}$} \\
\hline & & $1^{\text {st }}$ visit & $2^{\text {nd }}$ visit & $\begin{array}{l}\text { Upon } \\
\text { admission }\end{array}$ & $\begin{array}{l}\text { Three days } \\
\text { later }\end{array}$ & & & \\
\hline Total calcium (mg/dL) & $8.5-10.5$ & 8.15 & 6.1 & 6.6 & 9.53 & 9.7 & 10.6 & - \\
\hline Ionized cal cium (mg/dL) & $1.14-1.35$ & - & 0.67 & 0.62 & 1.10 & 1.89 & 1.29 & - \\
\hline Magnesium (mg/dL) & $1.5-2.55$ & - & - & 0.37 & 1.28 & 1.48 & 0.81 & 2.26 \\
\hline Phosphorus (mg/dL) & $3.2-6.3$ & 6.3 & - & - & - & - & - & - \\
\hline Alkaline phosphatase (U/L) & 35-307 & 212 & - & - & - & - & - & - \\
\hline Alanine transaminase $(\mathrm{U} / \mathrm{L})$ & $5-$ & - & & & & & & \\
\hline Parathyroid hormone $(\mathrm{pg} / \mathrm{mL})$ & $15-65$ & - & - & - & 25 & 25 & - & 36.13 \\
\hline
\end{tabular}




\section{REFERENCES}

[1] Walder RY, Landau D, Meyer P, Shalev $\mathrm{H}$, Tsolia M, Borochowitz Z, Boettger MB, Beck GE, Englehardt RK, Carmi R, Sheffield VC. Mutation of TRPM6 causes familial hypomagnesemia with secondary hypocalcemia. Nature genetics. 2002 Jun; 31(2): 171-4.

[2] Carrazza FR, Souza MS, Romaldini C, Feferbaun R, Diniz EA. Magnesium metabolism in chronic primary hypomagnesemia. J Pediatr (Rio J). 2000 Jul 1; 76(4): 310-4.

[3] Schlingmann KP, Sassen MC, Weber S, Pechmann U, Kusch K, Pelken L, Lotan D, Syrrou M, Prebble JJ, Cole DE, Metzger DL. Novel TRPM 6 mutations in 21 families with primary hypomagnesemia and secondary hypocalcemia. Journal of the American Society of Nephrology. 2005 Oct 1; 16(10): 3061-9.

[4] Zhao Z, Pei Y, Huang X, Liu Y, Yang W, Sun J, Si N, Xing X, Li M, Wang O, Jiang Y. Novel TRPM6 mutations in familial hypomagnesemia with secondary hypocalcemia. American journal of nephrology. 2013; 37(6): 541-8.

[5] Visudhiphan P, Visudtibhan A, Chiemchanya S, Khongkhatithum C. Neonatal seizures and familial hypomagnesemia with secondary hypocalcemia. Pediatric neurology. 2005 Sep 1; 33(3): 202-5.

[6] Shalev H, Phillip M, Galil A, Carmi R, Landau D. Clinical presentation and outcome in primary familial hypomagnesaemia. Archives of disease in childhood. 1998 Feb 1; 78(2): 127-30.

[7] Katayama K, Povalko N, Yatsuga S, Nishioka J, Kakuma T, Matsuishi T, Koga Y. New TRPM6 mutation and management of hypomagnesaemia with secondary hypocalcaemia. Brain and Development. 2015 Mar 1; 37(3): 292-8.

[8] Chubanov V, Gudermann T, Schlingmann KP. Essential role for TRPM6 in epithelial magnesium transport and body magnesium homeostasis. Pflügers Archiv. 2005 Oct; 451(1): 228-34.

[9] Singh R, Bhat MH, Bhansali A. Hypomagnesaemia masquerading as hypoparathyroidism. JOURNALASSOCIATION OF PHYSICIANS OF INDIA. 2006 May 1; 54(Y): 411.

[10] Apa H, Kayserili E, Agin H, Hizarcioglu M, Gulez P, Berdeli A. A case of hypomagnesemia with secondary hypocalcemia caused by Trpm6 gene mutation. The Indian Journal of Pediatrics. 2008 Jun; 75(6): 632-4. 
[11]Lainez S, Schlingmann KP, Van Der Wijst J, Dworniczak B, Van Zeeland F, Konrad M, Bindels RJ, Hoenderop JG. New TRPM6 missense mutations linked to hypomagnesemia with secondary hypocalcemia. European Journal of Human Genetics. 2014 Apr; 22(4): 497504. 